\title{
The role of NO system in low back pain chronicity
}

\author{
Vera V. Trefilova ${ }^{1,2^{*}}$, Natalia A. Shnayder ${ }^{2,3^{*}}$, Tatyana E. Popova ${ }^{4}$, Olga V. Balberova ${ }^{5}$ and Regina F. Nasyrova ${ }^{2^{*}}$ \\ 1 The Hospital for War Veterans, 193079, St. Petersburg, Russian Federation; gvv@zdrav.spb.ru; \\ 2 V.M. Bekhterev National Research Medical Center for Psychiatry and Neurology, Saint-Petersburg, Russian \\ Federation; spbinstb@bekhterev.ru \\ 3 V. F. Voino-Yasenetsky Krasnoyarsk State Medical University, 660022, Krasnoyarsk, Russian Federation; \\ rector@krasgmu.ru; \\ 4 Yakutsk Scientific Center for Complex Medical Problems, 677000, Yakutsk, Russian Federation; \\ ynckmp@yandex.ru; \\ 5 The Ural State University of Physical Culture, 454091, Chelyabinsk, Russian Federation; uralacad- \\ emy@mail.ru; \\ * Correspondence: vermutdoc@gmail.com, Tel.: +7-(812)-670-89-37 (V.V.T); nataliashnayder@gmail.com \\ (N.A.S.); nreginaf77@gmail.com (R.F.N.); Tel.: +7-(812)-620-02-20 (N.A.S. and R.F.N.)
}

\begin{abstract}
Citation: Trefilova, V.V.; Shnayder, N.A.; Popova, T.E.; Balberova, O.V.; Nasyrova, R.F. The role of NO system in low back pain chronification. Personalized Psychiatry and Neurology 2021, 1 (1): 37-45

Chief Editor: Nikolay G. Neznanov, D Med Sci, Professor

Received: 06 April 2021

Accepted: 12 April 2021

Published: 25 April 2021

Publisher's Note: V. M. Bekhterev NMRC PN stays neutral with regard to jurisdictional claims in published maps and institutional affiliations
\end{abstract}

Copyright: $@ 2021$ by the authors.

\begin{abstract}
Low back pain (LBP) is an important interdisciplinary medical problem, in the development of which various molecular genetics, pathomorphological and pathobiomechanical mechanisms play a role. Intervertebral disc degeneration (IVDD), facet joints arthrosis and myofascial syndrome are the most important pathological processes associated with chronic lower back pain in adults. The nitric oxide (NO) system may play one of the key roles in the development of LBP and its chronicity. (1): Background: The review of publications which are devoted to changes in the NO system in patients with LBP. (2): Materials: We have carried out a search for Russian-language and English-language full-text articles published in e-Library, PubMed, Oxford Press, Clinical Case, Springer, Elsevier, Google Scholar databases. The search was carried out using keywords and their combinations. The search depth was 10 years (2011-2021). (3): Results: Role of NO and various NOsynthase (NOS) isoforms in LBP process demonstrated primarily from animal models to humans. The most studied are the neuronal NOS (nNOS). The role of inducible nose (iNOS) and endothelial (eNOS) - continues to be studied. Associative genetic studies have shown that single nucleotide variants (SNV) of genes encoding all three NOS isoforms (nNOS, NOS1 gene; iNOS, NOS2 gene; eNOS, NOS3 gene) may be associated with chronic LBP. Prospects for the use of NOS inhibitors to modulate the effect of drugs used to treat back pain are discussed. (4): Conclusion: Associative genetic studies of SNV NOS1, NOS2, NOS3 genes are important for understanding genetic predictors of LBP chronicity and development of new personalized pharmacotherapy strategies.
\end{abstract}

Keywords: intervertebral disc; degeneration; facet joints arthrosis; myofascial syndrome; low back pain; nitric oxide; nitric oxide synthase (NOS); gene; genetics; genetic predisposition.

\section{Introduction}

Low back pain (LBP) is an important interdisciplinary medical problem. Various molecular genetics, pathomorphological, and pathobiomechanical mechanisms play a role in LBP development (Figure 1). Globally, years lived with disability caused by LBP increased by $54 \%$ between 1990 and 2015 [1]. About 2-7\% of people with acute LBP experience chronic pain in later stages. Some studies have shown that chronic LBP ( $>3$ months) affects an estimated $15-45 \%$ of the population. It is also the most common cause of disability in individuals between the ages of 45 and 65 years [2]. Annually, the prevalence of low back pain in the general United States (US) adult population is $10-30 \%$, and the lifetime prevalence of US adults is as high as 65-80\% [3] According to Russian authors, episodes of back pain occur annually in $36 \%$ the adults, regress on their own or during treatment 
in $54-90 \%$ of cases. However, back pain relapses are observed in $24-80 \%$ of patients within a year. Among the causes of disability and in general for the aggregate of economic losses, LBP over the past few years it has come out on top. The peak incidence of LBP occurs at the mature age of 30 up to 59 years, after 65 years the incidence of back pain decreases [4]. Most new episodes of LBP are accompanied by a quick recovery. However, LBP-associated syndromes leading to temporary disability are common, and in some patients, LBP becomes permanent, leading to high rates of disability. The socio-economic significance of the disease is due to its prevalence among patients of able-bodied age, as a result of which there are significant economic losses (insurance payments and decrease in labor efficiency during the period remission) [5].

Chronic pain syndromes associated with LBP lead to significant economic losses in the US [6]. In the US 20 million people suffer from chronic pain, the economic damage is 50 billion dollars per year, and compensation payments to patients with spinal diseases due to temporary working capacity - 200 million dollars per year. Expenses for LBP treatment is 2-3 times higher than the cost for cancer treatment [7]. In Europe the socio-economic burden of LBP is also very high. A minority of patients visit secondary or tertiary care because of severe and long-lasting complaints. This subgroup may account for a major part of disability and costs, yet could potentially gain most from treatment.

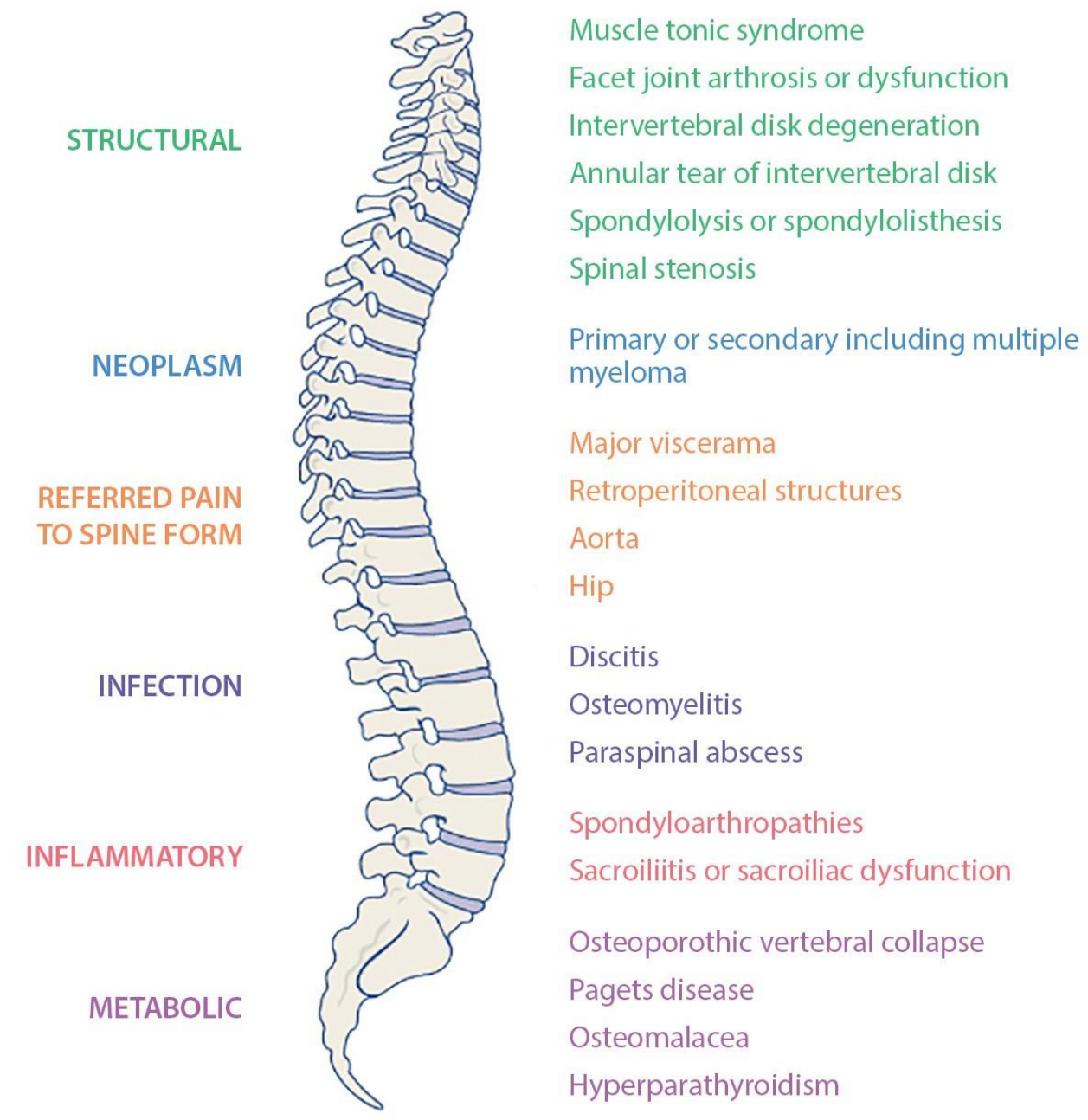

Figure 1. Causes of the low back pain in humans. 

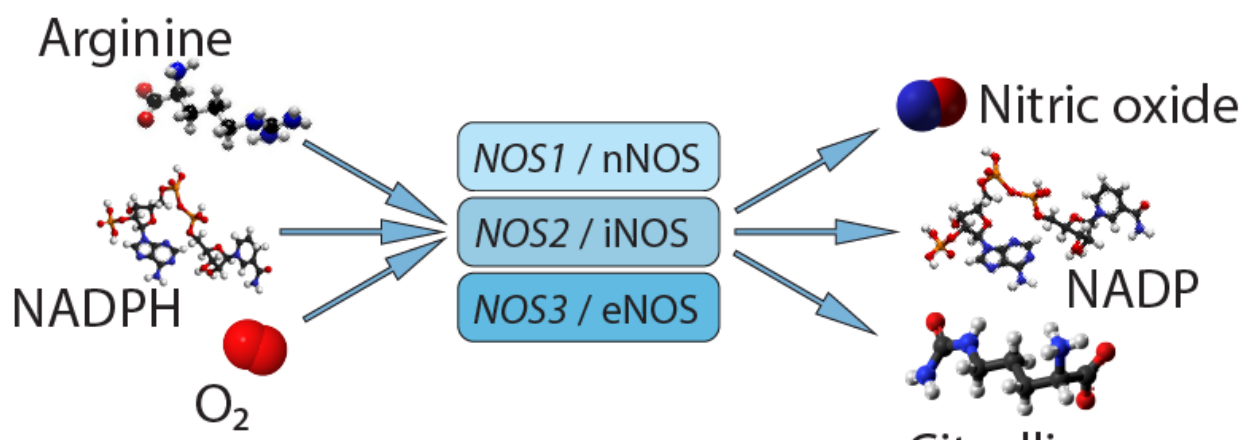

Citrulline

Figure 2. Synthesis of nitric oxide.

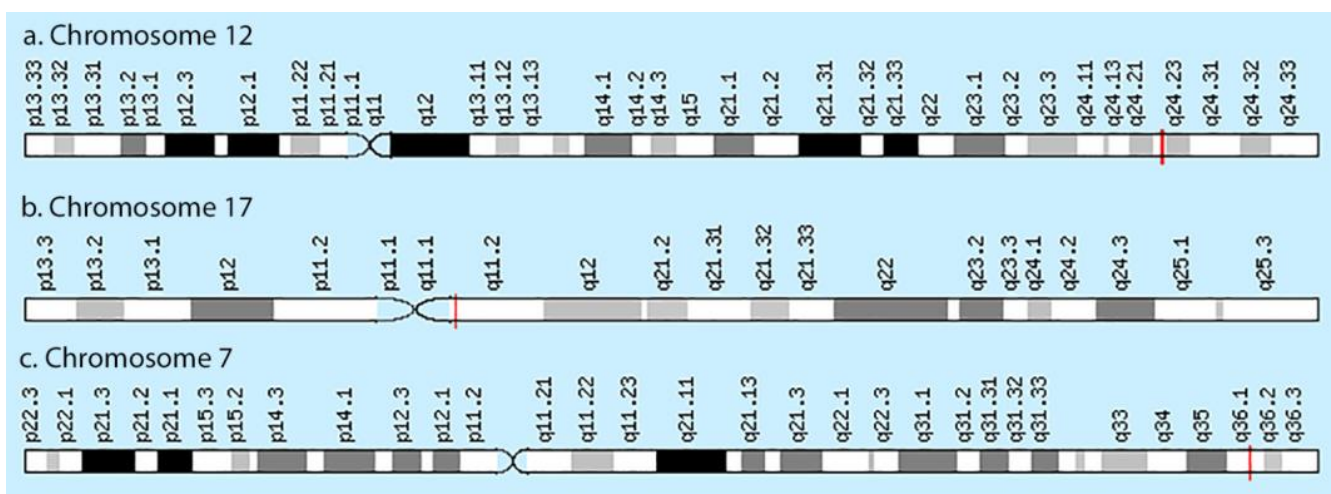

Figure 3. Localization of NOS1 (a), NOS2 (b) and NOS3 (c) genes.

Almost half of the insurance costs could be contributed to LBP-related care. Higher LBP-related costs (€4015 per year) were reported in patients with discogenic LBP referred to specialized pain care [8].

Intervertebral disk degeneration (IVDD), facet joints arthrosis and myofascial syndrome are the most important pathological processes associated with chronic LBP in adults. Standard approaches to the treatment of LBP do not solve the problem of chronic pain syndrome. This is the reason for the search for new personalized strategies for the prevention and therapy of LBP. The nitric oxide (NO) system can play one of the key roles in the development of LBP and its chronicity.

$\mathrm{NO}$ is involved in numerous physiological processes in the peripheral and central nervous system. It is produced intracellularly by the catabolism of Larginine to L-citrulline by NO synthase enzyme (NOS), which is present in three isoforms, the neuronal (nNOS), endothelial (eNOS) and inducible (iNOS) isoforms (Figure 2). The role NO in pain plays is not simple, since it may show pro- or anti-nociceptive effects depending on the circumstances. The majority of data, in preclinical studies support a pronociceptive role of NO at the spinal level. Yet, other studies show inconsistent results [9]. NOS1, NOS2 and NOS3 genes (Figure 3) are implicated in the production of nNOS, iNOS and eNOS [10].

\section{Objective}

The purpose of the study is review of Russian-language and English-language publications, which are devoted to changes in the nitric oxide system in patients with LBP. 
We have carried out a search for Russian-language and English-language full-text articles published in e-Library, PubMed, Oxford Press, Clinical Case, Springer, Elsevier, Google Scholar databases. The search was carried out using keywords and their combinations, including: intervertebral disc, degeneration, facet joints arthrosis, myofascial syndrome, low back pain, nitric oxide, nitric oxide synthase (NOS), gene, genetics, genetic predisposition. The search depth was 10 years (2011-2021). In addition, this review includes articles of historical interest. Despite an extensive search, it is possible that we might have missed some studies published in recent years.

\section{Results}

The NO system and low back pain

LBP is a progressive and debilitating disease with multifactorial causes (IVDD, arthrosis of the facet joints, muscular tonic syndrome, etc.).

However, the mechanisms of chronic LBP are poorly understood. At the same time, IVDD and arthrosis of the facet joints are considered as the two leading causes of this disorder [11].

$\mathrm{NO}$ is an oxygen free radical which is involved in variety physiological and pathological events. NO concentration may increase in the perifacetal region, and perifacetal NO levels in patients with LBP of higher compared with healthy people.

Brisby H. et al. (2007) showed, that patients with chronic LBP have 3-fold higher level of $\mathrm{NO}$ in the perifacetal region compared to the healthy controls $(1.66 \pm 1.39 \mathrm{vs} 0.46 \pm 0.37$ $\mathrm{nM}, p=0.007)$. However, the authors did not find an association between NO level and pain duration or pain level, which was rated on the visual analogue scale (VAS). Research has shown that higher NO level in the perifacetal region may be the biomarker of chronic LBP in patients with facet joint arthrosis. The findings of higher NO level in the perifacetal region in chronic LBP patients compared to healthy controls indicate that the degenerative process of the joints may cause increased NO production. Patients that responded to corticosteroid/local anaesthetic infiltration had higher NO level in the perifacetal region compared to patients without response [12].

The role of different NOS isoforms in LBP process is derived primarily from animal models [13]. While nNOS is mainly observed at the spinal level or in neuropathic pain models, iNOS is up-regulated in inflamed tissues [14] and is involved in the development of hyperalgesia in inflammatory and neuropathic pain models [15]. Jensen L et al. (2015) investigated the role of nNOS in the mechanism of chronic muscle pain development on the example of trapezius myalgia in 42 women with clinically diagnosed neck pain. The authors showed that sarcolemmal nNOS expression is irregular and absent from selected fibers in the trapezius muscle. Moreover, they found an increase in sarcoplasm-localized nNOS in women with trapezius myalgia, which was essentially normalized by 10 weeks of specific strength training. Abnormalities in nNOS expression show a potential of predicting the progression of muscle damage and pain, and correcting the dislocation of nNOS may prove essential in treatment of work-related muscle pain [16]. Kohyama K et al. (2000) showed that changes in the level of NO can be associated with intervertebral disk due to the induction of apoptosis of intervertebral disk cells [17].

Oxidative stress is a cellular state with an increased level of reactive oxygen species (ROS) that is caused by an imbalance of generation and removal of these species. Singlet oxygen, superoxide anions, hydroxyl radicals, and NO are examples of ROS synthesized in intervertebral disk cells [18]. In intervertebral disk tissues, oxidative stress may initiate or participate in matrix destruction and cell apoptosis, which ultimately result in IVDD [19]. It has been shown that the increase of exogenous NO may promote cell apoptosis 
and suppress proteoglycan synthesis in cultured disk cells. NO has been demonstrated to participate in the IVDD induced by mechanical stress or interleukin 1 (IL1) [17,20-23].

Liu G.Z. et al. (2001) and Rannou F. et al. (2003) demonstrated that NO mediates the change of proteoglycan synthesis in the annulus fibrosus cells of the human intervertebral disc [21-22].

\section{Association of SNV of NOS genes with low back pain development}

In order to determine the role of SNV of genes NOSs in herniation of the lumbar intervertebral disk in humans, a case-control study was carried out with the participation of 179 adult individuals, according to the results of which SNV NOS3 rs2070744 (-786 T/C) and NOS2 rs1060826 (22 G/A) were more common among the control group than in patients with symptoms of hernia of the lumbar intervertebral disk, including those with pain syndrome, which indicates their possible protective role against hernia of the lumbar intervertebral disk. Genotyping of these SNV can be useful in identifying individuals with an increased lifetime risk of disc herniation, in whom measures to prevent disc herniation in the lumbar spine can be applied. This study also examined polymorphism NOS3 4a4b (27-bp variable number of tandem repeat (VNTR) polymorphism in intron 4), however, when comparing the genotypic and allelic frequencies of this SNV genotyped in patients with hernia of the lumbar intervertebral disk and in the control group, no significant differences were observed [24]. In a later study among the patients with the IVDD in a young Korean population, the disc degeneration severity score was analyzed according to the genotypes of VEGF and eNOS. The results showed that the frequencies of NOS3 $786 \mathrm{TC}+\mathrm{CC}(21.6 \%)$, and $894 \mathrm{GT}+\mathrm{TT}(27.5 \%)$ were higher in the patients compared with controls. However, no statistically significant differences between patients and controls were found [25].

Despite the fact, the expression of nNOS, which is encoded by the NOS1 gene is shown in the intervertebral discs structures [11] and in skeletal muscles [26]. The prognostic role of the NOS1 gene of SNV in the development of back pain in patients with IVDD, facet joints arthrosis, and muscle-tonic syndromes has not yet been studied.

\section{The role of NOS modulators in the treatment of low back pain}

Non-steroid anti-inflammatory drugs (NSAIDs) are among the most prescribed medications for the patients with LBP, yet their efficacy is com-promised by a ceiling analgesic effect. The inhibitory effect of NSAIDs on NO production has been reported in many studies both clinically [27] and experimentally [28-29]. The involvement of the NO-cGMP pathway in the antinociceptive effects of NSAIDs has been suggested in several experimental studies [30-31].

Hamza M. et al. (2010) studied the effect of ketorolac on NO production and NOSs gene expression. The authors showed significantly higher levels of NO at the first $100 \mathrm{~min}$ compared to the last 80 minutes in the placebo treated group. In the patients which treated ketorolac NO level gradually decreased over the first $60 \mathrm{~min}$ but was similar to placebo over the later 100 -180 min, with no significant change in NO level over time. The levels of NO were negatively correlated to pain intensity scores. While the gene expression of iNOS and eNOS were not up-regulated, 3 hours after surgery, nNOS was downregulated in both treatment groups and NOS3 gene expression was significantly lower in the ketorolac group compared to the placebo group [32].

Intradermal administration of the NOS substrate L-Arg or the NO donor SIN-1, both of which elevate NO levels, cause a dose-dependent mechanical hyperalgesia [33]. However, as intracutaneous injection of NO in healthy volunteers evokes pain in a dose dependent manner [34], while transdermal application of the NO donor glyceryl trinitrate improved pain in patients with shoulder pain syndrome [35]. 
The research by Fujioka Y et al. (2016) showed that gene NOS1 expression associated with inflammatory and neuropathic pain was upregulated at days 1 and 3 in the dorsal root ganglion following disc puncture; it might serve as a therapeutic target for lumbar disc herniation. It is not known whether inhibitors of NOS1, such as L-NG-Nitroarginine methyl ester (L-NAME), are useful for low back pain and sciatica [36].

Kohyama K et al. (2000) studied biological understanding of IVDD. The authors showed a change in NOS2 expression in intervertebral disk cell culture obtained from the surgical specimen of the patients with lumbar IVDD with herniation. Suppression of $3 \mathrm{H}-$ Thymidine incorporation and DNA fragmentation in the disc cells were promoted by treatment of 100 microM NOC-18. These results suggest that the use of modulators of NO level and iNOS activity is important for slowing down the rate of IVDD development [17].

Yang X. et al. (2014) showed that the use of an antioxidant nanofullerol prevents IVDD. The authors hypothesize that antioxidants are potentially good therapeutic candidates to treat of IVDD, because of their ability to scavenge ROS that lead to the injury of cellular functions in intervertebral disk tissues. Fullerenes are extremely powerful antioxidants with unique nanostructures, and superior to conventional antioxidants due to their long-lasting activity and excellent cell membrane-penetrating ability. In this study, Yang $X$. et al. (2014) found that fullerol (a polyhydroxylated derivative of fullerene) had a preventive effect on IVDD, highlighting its potential use as a therapeutic agent for the treatment of LBP. Nanofullerol reduced the cytotoxicity and ROS of hydrogen peroxidetreated human nucleus pulposis cells and counteracted in vivo IVDD in a rabbit annuluspuncture model [18].

Nerlich A.G et al. (1997) reported that carboxymethyllysine (CML) is associated with ROS accumulation in the nucleus pulposus tissue, and that CML was closely related to IVDD [37]. The authors indicated that CML activated a receptor of advanced glycation end products (RAGE)-nuclear factor (NF)- $\kappa$ B system in aging and IVDD. The activation of RAGE-NFkB promoted the gene expression of NOSs and MMPs [19]. It is not clear whether nanofullerol defends IVDD by modifying CML and its signaling pathway, and this is currently under investigation [18].

Castania V. et al. (2017) analyzed the potential role of nNOS modulation in the tail needle puncture model of IVDD. Male Wistar rats were submitted to percutaneous disk puncture with a 21-gauge needle of coccygeal vertebras. The selective nNOS pharmacological inhibitor N ( $\omega$ )-propyl-L-arginine (NPLA) or a nNOS-target siRNA (siRNAnNOShum_4400) was injected immediately after the intervertebral disk puncture with a 30gauge needle. Signs of IVDD were analyzed by in vivo MRI and histological score. The authors found that intact intervertebral disks express low levels of nNOS mRNA. Disk injury caused a 4 -fold increase in nNOS mRNA content at $5 \mathrm{~h}$ post disk lesion. However, NPLA or nNOS-target siRNA slight mitigate IVDD progress. Further studies would disclose the nNOS role and its potential therapeutical value in IVDD [11].

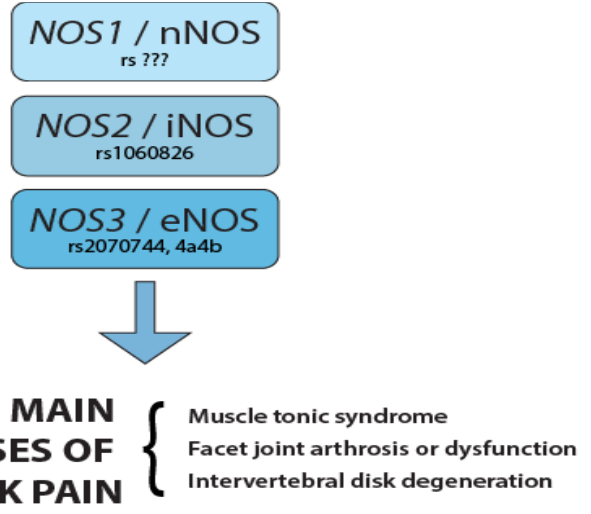

Figure 4. The role of SNV of NOSs genes in low back pain development. 
Current therapies for IVDD and facetal joints arthrosis with acute or chronical LBP may include nonsurgical treatment with NO modalities $[20,38]$ in presurgical and postsurgical periods in the patients with intervertebral disk herniation [39-40]. However, neither nonsurgical nor surgical therapy restore functional native intervertebral disk tissue, or regenerate the degenerated intervertebral disk tissue, resulting in chronic inflammatory back pain. In recent years, numerous studies have demonstrated that oxidative stress and local NO levels play an important role in the IVDD progression initiation [19,23,41-42] and back pain $[12,15]$.

\section{Discussion}

Thus, the three leading pathomorphological processes that cause chronicity of LBP are associated with changes in the NO system (Figure 4). The review demonstrated that changes in the NO system play an important role in LBP development and chronicity in humans. Local NO and NOS levels increase in patients with facet joints arthrosis, skeletal muscle tension and inflammation, IVDD also [12,16-17]. These mechanisms are important for our understanding of the pathogenesis of LBP as one of the most common chronic neurological diseases in adult patients [2]. This may form the basis for a personalized approach to multimodal therapy for chronic pain syndrome using NOS modulators, which have been previously studied in animal models and humans [11,17-19,36]. In addition, the effect of currently widely used drugs for LBP (NSAIDs, non-opioid and opioid analgesics, antidepressants, anticonvulsants-gabapentinoids, etc.) on the NO system is important to consider in the pathological processes under consideration. A promising new therapeutic strategy is the modulation of NOS activity through the use of L-NAME [36], NOC-18 [17], nanofullerol [18], NPLA and siRNAn-NOShum_4400 [11].

\section{Conclusions}

Associative genetic research of SNV NOS1, NOS2, NOS3 genes is important for understanding the genetic predictors of LBP chronicity and developing new personalized pharmacotherapy strategies. However, a large multicentral randomized genetic and clinical studies are necessary for translation the results in real clinical practice.

Author Contributions: Conceptualization, T.V.V., O.V.B. and N.A.S.; methodology, N.A.S. and R.F.N.; writing - original draft preparation, T.V.V. and O.V.B.; writing-review and editing, N.A.S. and T.E.P.; visualization, T.V.V.; supervision, R.F.N.; project administration, T.E.P. All authors have read and agreed to the published version of the manuscript.

Funding: This research received no external funding.

Acknowledgments: The authors thank Evgeniy A. Trevilov for the technical assistance in preparing all the figures.

Conflicts of Interest: The authors declare no conflict of interest.

\section{References}

1. Hartvigsen, J.; Hancock, M.J.; Kongsted, A.; Louw, Q.; Ferreira, M.L.; Genevay, S.; Hoy, D.; Karppinen, J.; Pransky, G.; Sieper, J.; Smeets, R.J.; Underwood, M. Lancet Low Back Pain Series Working Group. What low back pain is and why we need to pay attention. Lancet 2018, 391, 2356-2367, doi:10.1016/S0140-6736(18)30480-X.

2. Alleva, J.; Hudgins, T.; Belous, J.; Kristin Origenes A. Chronic low back pain. Dis Mon. 2016, 62, 330-333, doi:10.1016/j.disamonth.2016.05.012.

3. Urits, I.; Burshtein, A.; Sharma, M.; Testa, L.; Gold, P.A.; Orhurhu, V.; Viswanath, O.; Jones, M.R.; Sidransky, M.A.; Spektor, B.; Kaye, A.D. Low Back Pain, a Comprehensive Review: Pathophysiology, Diagnosis, and Treatment. Curr Pain Headache Rep. 2019, 23, 23, doi:10.1007/s11916-019-0757-1. PMID: 30854609. 
4. Zinovieva, O.E.; Rozhkov, D.O. Multidisciplinary approach to the treatment of chronic nonspecific back pain. Analysis of the clinical case. RMJ. 2018, 4, 93-96.

5. Motina, A.N.; Astashchenko, Ya.A.; Masaleva, I.O.; Tretyakova E.E. The social hygienic characteristic of patients with osteochondrosis of spine. Probl Sotsialnoi Gig Zdravookhranenniiai Istor Med. 2020, 28, 396-399, Russian, doi:10.32687/0869-866X-202028-3-396-399.

6. Dagenais, S.; Caro, J.; Haldeman, S.; A systematic review of low back pain cost of illness studies in the United States and internationally. Spine J. 2008, 8, 8-20, doi:10.1016/ j.spinee.2007.10.005.

7. Balyazin, V. Pain - multidisciplinary problem of medicine. Chief physician of the south of Russia 2018, 2, 4-6, Russian.

8. Dutmer, A.L.; Schiphorst, P.; Henrica, R.; Soer, R.; Brouwer, S.; Bültmann, U.; Dijkstra, P.U.; Coppes, M.H.; Stegeman, P.; Buskens, E.; van Asselt, A.D.I.; Wolff, A.P.; Reneman, M.F. Personal and Societal Impact of Low Back Pain. Spine 2019, 44, 14431451, doi:10.1097/BRS.0000000000003174.

9. Kang, J.D.; Stefanovic-Racic, M.; McIntyre, L.A; Georgescu, H.I.; Evans, C.H. Toward a biochemical understanding of human intervertebral disc degeneration and herniation. Contributions of nitric oxide, interleukins, prostaglandin E2, and matrix metallopro-teinases. Spine (Phila Pa 1976) 1997, 22, 1065-1073, doi:10.1097/00007632-199705150-00003.

10. González-Castro, T.B.; Genis-Mendoza, A.D.; Tovilla-Zárate, C.A.; Juárez-Rojop, I.E.; López-Narvaez, M.L.; Pé-rez-Hernández, N.; Rodríguez-Pérez, J.M.; Martínez-Magaña, J.J. Association between polymorphisms of NOS1, NOS2 and NOS3 genes and suicide behavior: a systematic review and meta-analysis. Metab Brain Dis. 2019, 34, 967-977, doi:10.1007/s11011-019-00406-3.

11. Castania, V.; Issy, A.C.; Silveira, J.W.; et al. The Presence of the Neuronal Nitric Oxide Synthase Isoform in the Intervertebral Disk. Neurotox Res 2017, 31, 148-161, doi:10.1007/s12640-016-9676-7

12. Brisby, H.; Ashley, H.; Diwan, A.D. In vivo measurement of facet joint nitric oxide in patients with chronic low back pain. Spine (Phila Pa 1976) 2007, 32, 1488-1492, doi: 10.1097/BRS.0b013e318067dc97.

13. Miclescu, A.; Gordh, T. Nitric oxide and pain: 'Something old, something new'. Acta Anaesthesiol Scand. 2009, 53, 1107-1120, doi:10.1111/j.1399-6576.2009.02054.x.

14. Gühring, H.; Tegeder, I.; Lötsch, J.; Pahl, A.; Werner, U.; Reeh, P.W.; Rehse, K.; Brune, K.; Geisslinger, G. Role of nitric oxide in zymosan induced paw inflammation and thermal hyperalgesia. Inflamm Res. 2001, 50, 83-88, doi:10.1007/s000110050728.

15. De Alba, J.; Clayton, N.M.; Collins, S.D.; Colthup, P.; Chessell, I.; Knowles, R.G. GW274150, a novel and highly selective inhibitor of the inducible isoform of nitric oxide synthase (iNOS), shows analgesic effects in rat models of inflammatory and neuropathic pain. Pain 2006, 120, 170-181, doi:10.1016/j.pain.2005.10.028.

16. Jensen, L.; Andersen, L.L.; Schrøder, H.D.; Frandsen, U.; Sjøgaard, G. Neuronal nitric oxide synthase is dislocated in type I fibers of myalgic muscle but can recover with physical exercise training. Biomed Res Int. 2015, 26527, doi:10.1155/2015/265278.

17. Kohyama, K.; Saura, R.; Doita, M.; Mizuno, K. Intervertebral disc cell apoptosis by nitric oxide: biological understanding of intervertebral disc degeneration. Kobe J Med Sci. 2000, 46, 283-295.

18. Yang, X.; Jin, L.; Yao, L.; Shen, F.H.; Shimer, A.; Li, X. Antioxidative nanofullerol prevents intervertebral disk degeneration. Int J Nanomedicine. 2014, 9, 2419-2430, doi:10.2147/IJN.S60853.

19. Nerlich, A.G.; Bachmeier, B.E.; Schleicher, E.; Rohrbach H.; Paesold, G.; Boos, N. Immunomorphological analysis of RAGE receptor expression and NF-kappaB activation in tissue samples from normal and degenerated intervertebral discs of various ages. Ann N Y Acad Sci. 2007, 1096, 239-248, doi:10.1196/annals.1397.090.

20. Furusawa, N.; Baba, H.; Miyoshi, N; et al. Herniation of cervical intervertebral disc: immunohistochemical examination and measurement of nitric oxide production. Spine (Phila Pa 1976) 2001, 26, 1110-1116, doi:10.1097/00007632-200105150-00004.

21. Liu, G.Z.; Ishihara, H.; Osada, R.; Kimura, T.; Tsuji, H. Nitric oxide mediates the change of proteoglycan synthesis in the human lumbar intervertebral disc in response to hy-drostatic pressure. Spine (Phila Pa 1976) 2001, 26, 134-141, doi:10.1097/00007632200101150-00005.

22. Rannou, F.; Richette, P.; Benallaoua, M.; et al. Cyclic tensile stretch modulates proteoglycan production by intervertebral disc annulus fibrosus cells through production of nitrite oxide. J Cell Biochem. 2003, 90, 148-157, doi:10.1002/jcb.10608.

23. Studer, R.K.; Gilbertson, L.G.; Georgescu, H.; Sowa, G.; Vo, N.; Kang J.D. p38 MAPK inhibition modulates rabbit nucleus pulposus cell response to IL-1. J Orthop Res. 2008, 26, 991-998, doi:10.1002/jor.20604.

24. Paz Aparicio, J.; Fernández Bances, I.; López-Anglada Fernández, E.; Montes, A. H.; Paz Aparicio, A.; Pena Vázquez, J.; Ramos García, S.; Antón García, S.; López Fernández, P.; Valle-Garay, E.; Asensi, V. The IL-1ß (+3953 T/C) gene polymorphism associates to symptomatic lumbar disc herniation. European spine journal 2011, 20 (Suppl. 3), 383-389, doi:10.1007/s00586-011-1915-2.

25. Han, I.B.; Ropper, A.E.; Teng, Y.D.; Shin, D.A.; Jeon, Y.J.; Park, H.M.; Shin, D.E.; Park, Y.S.; Kim, K.N.; Kim, N.K. Associa tion between VEGF and eNOS gene polymorphisms and lumbar disc degeneration in a young Korean population. Genet Mol Res. 2013, 12, 2294-2305, doi:10.4238/2013.July.8.10.

26. Baldelli, S.; Lettieri Barbato, D.; Tatulli, G.; Aquilano, K.; Ciriolo, M.R. The role of nNOS and PGC-1 $\alpha$ in skeletal muscle cells. J Cell Sci. 2014, 127, 4813-4820, doi:10.1242/jcs.154229.

27. Vandivier, R.W.; Eidsath, A.; Banks, S.M.; Preas, H.L.; 2nd, Leighton, S.B.; Godin, P.J.; Suffredini, A.F.; Danner, R.L. Downregulation of nitric oxide production by ibuprofen in human volunteers. J Pharmacol Exp Ther. 1999, 289, $1398-1403$.

28. Gühring, H.; Hamza, M.; Sergejeva, M.; Ates, M.; Kotalla, C.E.; Ledent, C.; Brune, K. A role for endocannabinoids in indomethacin-induced spinal antinociception. Eur J Pharmacol. 2002, 454, 53-63, doi:10.1016/s0014-2999(02)02485-8. 
29. Ryu, Y.S.; Lee, J.H.; Seok, J.H.; Hong, J.H.; Lee, Y.S.; Lim, J.H.; Kim, Y.M.; Hur, G.M. Acetaminophen inhibits iNOS gene expression in RAW 264.7 macrophages: differential regulation of NF-kappaB by acetaminophen and salicylates. Biochem Biophys Res Commun. 2000, 272, 758-764, doi:10.1006/bbrc.2000.2863.

30. Granados-Soto, V.; Flores-Murrieta, F.J.; Castañeda-Hernández, G.; López-Muñoz, F.J. Evidence for the involvement of nitric oxide in the antinociceptive effect of ketorolac. Eur J Pharmacol. 1995, 277, 281-284, doi: 10.1016/0014-2999(95)00123-3.

31. Ventura-Martínez, R.; Déciga-Campos, M.; Díaz-Reval, M.I.; González-Trujano, M.E.; López-Muñoz, F.J. Peripheral involvement of the nitric oxide-cGMP pathway in the indomethacin-induced antinociception in rat. Eur J Pharmacol. 2004, 503, 43-48, doi:10.1016/j.ejphar.2004.09.018.

32. Hamza, M.; Wang, X.M.; Wu, T.; Brahim, J.S.; Rowan, J.S.; Dionne, R.A. Nitric oxide is negatively correlated to pain during acute inflammation. Mol Pain. 2010, 6, 55, doi:10.1186/1744-8069-6-55.

33. Aley, K.O.; McCarter, G.; Levine, J.D. Nitric oxide signaling in pain and nociceptor sensitization in the rat. J Neurosci. 1998, 18, 7008-7014, doi:10.1523/JNEUROSCI.18-17-07008.1998.

34. Holthusen, H.; Arndt, J.O. Nitric oxide evokes pain in humans on intracutaneous injec-tion. Neurosci Lett. 1994, 165, 71-44, doi:10.1016/0304-3940(94)90712-9.

35. Berrazueta, J.R.; Losada, A.; Poveda. J.; Ochoteco, A.; Riestra, A.; Salas, E.; Amado, J.A. Successful treatment of shoulder pain syndrome due to supraspinatus tendinitis with transdermal nitroglycerin. A double-blind study. Pain 1996, 66, 63-67, doi:10.1016/0304-3959(96)03021-7.

36. Fujioka, Y.; Stahlberg, A.; Ochi, M.; Olmarker, K. Expression of inflammation/pain-related genes in the dorsal root ganglion following disc puncture in rats. J Orthop Surg. 2016, 24, 106-112, doi:10.1177/230949901602400124.

37. Nerlich, A.G.; Schleicher, E.D.; Boos, N. Immunohistologic markers for age-related changes of human lumbar intervertebral discs. Spine (Phila Pa 1976) 1997, 22, 2781-2795, doi:10.1097/00007632-199712150-00001.

38. Ziskoven, C.; Jager, M.; Kircher, J.; et al. Physiology and pathophysiology of nitrosative and oxidative stress in osteoarthritic joint destruction. Can J Physiol Pharmacol. 2011, 89, 455-466, doi:10.1139/y11-055.

39. Freemont, T.J.; LeMaitre, C.; Watkins, A.; Hoyland, J.A. Degeneration of intervertebral discs: current understanding of cellular and molecular events, and implications for novel therapies. Expert Rev Mol Med. 2001, 2001, 1-10, doi:10.1017/S1462399401002885.

40. Slade, S.C.; Keating, J.L. Unloaded movement facilitation exercise compared to no exercise or alternative therapy on outcomes for people with nonspecific chronic low back pain: a systematic review. J Manipulative Physiol Ther. 2007, 30, 301-311, doi:10.1016/j.jmpt.2007.03.010.

41. Kim K.W.; Ha, K.Y.; Lee, J.S.; Rhyu, K.W.; An, H.S.; Woo, Y.K. The apoptotic effects of oxidative stress and antiapoptotic effects of caspase inhibitors on rat notochordal cells. Spine (Phila Pa 1976) 2007, 32, 2443-2448, doi:10.1097/BRS.0b013e318157395a.

42. Gruber, H.E.; Hoelscher, G.L.; Ingram, J.A.; Bethea, S.; Hanley, E.N. IGF-1 rescues human in-tervertebral annulus cells from in vitro stress-induced premature senescence. Growth Factors 2008, 26, 220-225, doi:10.1080/08977190802273814. 